University of South Carolina

Scholar Commons

7-2007

\title{
Perceived Individual, Social, and Environmental Factors for Physical Activity and Walking
}

\author{
Michelle L. Granner \\ Patricia A. Sharpe \\ University of South Carolina - Columbia, SHARPEP@mailbox.sc.edu \\ Brent E. Hutto \\ Sarah Wilcox \\ University of South Carolina - Columbia, swilcox@sc.edu \\ Cheryl L. Addy \\ University of South Carolina - Columbia, caddy@sc.edu
}

Follow this and additional works at: https://scholarcommons.sc.edu/

sph_physical_activity_public_health_facpub

Part of the Public Health Commons

\section{Publication Info}

Published in Journal of Physical Activity and Health, Volume 4, Issue 3, 2007, pages 278-293.

Granner, M. L., Sharpe, P. A., Hutto, B., Wilcox, S., \& Addy, C. L. (2007). Perceived individual, social, and environmental factors for physical activity and walking. Journal of Physical Activity and Health, 4(3), 278-293.

(c) Journal of Physical Activity and Health, 2007, Human Kinetics

This Article is brought to you by the Physical Activity and Public Health at Scholar Commons. It has been accepted for inclusion in Faculty Publications by an authorized administrator of Scholar Commons. For more information, please contact digres@mailbox.sc.edu. 


\title{
Perceived Individual, Social, and Environmental Factors for Physical Activity and Walking
}

\author{
Michelle L. Granner, Patricia A. Sharpe, Brent Hutto, \\ Sara Wilcox, and Cheryl L. Addy
}

\begin{abstract}
Background: Few studies have explored associations of individual, social, and environmental factors with physical activity and walking behavior. Methods: A random-digit-dial questionnaire, which included selected individual, social, and environmental variables, was administered to 2025 adults, age $18 \mathrm{y}$ and older, in two adjacent counties in a southeastern state. Logistic regressions were conducted adjusting for age, race, sex, education, and employment. Results: In multivariate models, somewhat different variables were associated with physical activity versus regular walking. Self-efficacy $(\mathrm{OR}=19.19)$, having an exercise partner $(\mathrm{OR}=1.47)$, recreation facilities $(\mathrm{OR}=1.54)$, and safety of trails from crime $(\mathrm{OR}$ $=0.72)$ were associated with physical activity level; while self-efficacy $(\mathrm{OR}=$ $4.22)$, known walking routes $(\mathrm{OR}=1.54)$, recreation facilities $(\mathrm{OR}=1.57-1.59)$, and safety of trails from crime $(\mathrm{OR}=0.69)$ were associated with regular walking behavior. Conclusions: Physical activity and walking behaviors were associated with similar variables in this study.
\end{abstract}

Key Words: exercise, community, ecological, promotion, behavior

The benefits of physical activity for reducing chronic disease morbidity and mortality are well established; ${ }^{1,2}$ however most adults in the US are not regularly active. ${ }^{3}$ Walking is the most frequently reported activity among adults who meet health recommendations for regular physical activity. ${ }^{4}$ Consistent with ecological models (that emphasize the complex interaction of multiple levels of influence on behavior), ${ }^{5-8}$ several studies have reported that physical activity and walking are associated with multiple factors from one or two levels of influence (individual, interpersonal, environmental). ${ }^{9-18}$

There are, however, only a few studies to date that have concurrently explored associations of individual, social, and environmental factors with physical activity and walking behavior from an ecologic perspective using constructs from all three levels, which may facilitate comparisons. These studies have reported physical activity $^{18-22}$ and walking behavior ${ }^{18-20,23}$ to be associated with several different

Granner is with the School of Public Health, University of Nevada, Reno, NV 89557. Sharpe, Hutto, Wilcox, and Addy are with the Arnold School of Public Health, University of South Carolina, Columbia, SC 29208. 
individual, social, and environmental (both perceived and objectively measured) factors, such as presence and condition of sidewalks, good street lighting, perceptions of neighborhood aesthetics, street connectivity, proximity and access to facilities/destinations, and presence of active people in the neighborhood. Multivariate models have found individual, social, and environmental factors contribute to both physical activity and walking. ${ }^{18-21,23}$ In some cases the magnitude of these associations have been roughly similar across levels of physical activity or across levels of walking, ${ }^{19,22,23}$ but in others, individual or social factors were somewhat more strongly associated with behavior than environmental factors. ${ }^{18,21}$ In addition, variables significantly associated with physical activity behaviors have differed when examining transportation-related compared to recreational physical activity, ${ }^{22}$ when examining moderate and vigorous physical activity compared to walking, ${ }^{18}$ and when examining physical activity compared to walking. ${ }^{19-21,23}$ Due, at least in part, to these differential findings in the literature, several authors have suggested that examination of specific physical activity types (e.g., walking) could contribute a better understanding of barriers and of how to more effectively motivate or promote these specific activities. ${ }^{5,19,22,24}$ Given that walking is a common and easily accessible form of physical activity, additional investigation of influencing factors on walking specifically could enhance our ability to promote health-related activity. ${ }^{16}$ Studies that have explored variables from individual, social, and environmental domains have contributed to our understanding of ecological influences on physical activity and walking behavior, but continued research is needed to explore additional potential influences from the universe of ecological factors and to extend the evidence. The purpose of this study was to examine the associations of selected perceived individual, social, and environmental factors with overall physical activity level, and with walking level specifically, in a diverse sample of adults from a southeastern state.

\section{Methods}

A list-assisted random digit-dialed telephone survey was conducted with 2025 noninstitutionalized adults age $18 \mathrm{y}$ and older residing in telephone-equipped dwellings in two adjacent counties in South Carolina. The average length of the interview was 18.6 min. The survey was conducted by ORC Macro of Burlington, Vermont. Within households, the next-birthday method of respondent selection was used. The next-birthday method of respondent selection asks the informant to identify the adult in the household who will have the next birthday and this adult is then selected for participation in the study (following informed consent). Interviews occurred between May 15 and June 23, 2003.

At least 15 attempts were made to reach unanswered calls, at multiple times of day and days of the week. Once an eligible adult was identified, as many calls as necessary were made to survey the selected adult. Initial refusals were re-contacted after $3 \mathrm{~d}$ by specially trained interviewers in an effort to reverse the refusal. At least $10 \%$ of interviews were monitored for quality assurance. Data were entered via a Computer Assisted Telephone Interview database.

The CASRO response rate $(32.9 \%$ in our study) is an outcome rate with the number of completed interviews in the numerator and an estimate of the number of eligible units in the sample in the denominator. There were 6810 eligible units 
in the denominator. The cooperation rate was $44.8 \%$, which is the proportion of all respondents interviewed over all eligible units ever contacted [complete interviews/ (complete interviews + refusals + terminations) $]-[2237 /(2237+2761+0)]$.

The survey's weights were calculated using differential probabilities of selection and a post-stratification factor adjusting weighted totals to 2000 Census population figures by age, race/ethnicity, and sex. Given the sampling design and the attendant weighting, the overall precision of the sample is $+1.10 \%$, with an average design effect of 0.83 (representing a relatively small degree of sampling error due to the design's departure from a simple random sample).

\section{Subjects}

The purpose of the telephone survey was to collect baseline data prior to a community-based intervention; therefore this study represents a secondary data analysis of cross-sectional data. A total of 2025 adults were interviewed. This study used race/ethnicity categories of African American, Caucasian, and other respondents $(n=$ 1997) due to the relatively small numbers of respondents who identified themselves to be of specific racial/ethnic categories other than African American or Caucasian $(n=78)$. Table 1 presents the characteristics of the sample and comparative data from the 2000 Census for both counties combined. The unweighted frequencies

Table 1 Sample Characteristics and Comparative Data from 2000 Census: Adults $>18$ Years (except where noted)

\begin{tabular}{|c|c|c|c|c|c|}
\hline \multirow[b]{2}{*}{ Variable } & \multicolumn{3}{|c|}{$\begin{array}{l}\text { Sample } \\
n=2025\end{array}$} & \multicolumn{2}{|c|}{$\begin{array}{c}2000 \text { Census } \\
n=230,407\end{array}$} \\
\hline & $n$ & $\%$ & $\begin{array}{l}\text { Weighted } \\
\%^{\mathrm{a}}\end{array}$ & $n$ & $\%$ \\
\hline \multicolumn{6}{|l|}{ Race } \\
\hline African American & 658 & 33.0 & 36.0 & 98,353 & 42.7 \\
\hline Caucasian & 1261 & 63.1 & 59.8 & 126,001 & 54.7 \\
\hline Other & 78 & 3.9 & 4.2 & 6053 & 2.6 \\
\hline Sex $($ total $n)$ & & & & 168,387 & \\
\hline Female & 1158 & 59.6 & 53.2 & 90,339 & 53.6 \\
\hline Male & 784 & 40.4 & 46.8 & 78,048 & 46.4 \\
\hline Age $($ total $n)$ & & & & 168,387 & \\
\hline $18-34$ y & 683 & 35.0 & 32.7 & 54,163 & 32.2 \\
\hline $35-54 y$ & 812 & 41.6 & 39.2 & 67,375 & 40.0 \\
\hline$>55 \mathrm{y}$ & 459 & 23.4 & 28.1 & 46,849 & 27.8 \\
\hline Education (total $n$ ) & & & & 145,048 & $*$ \\
\hline Less than high school & 223 & 11.2 & 12.4 & 38,253 & 26.4 \\
\hline High school graduate & 593 & 29.8 & 30.0 & 43,990 & 30.3 \\
\hline Some college & 1089 & 54.8 & 53.3 & 37,543 & 25.9 \\
\hline$>4$ y of college & 82 & 4.1 & 4.4 & 25,262 & 17.4 \\
\hline $\begin{array}{l}\text { Employed outside the home } \\
\text { (total } n \text { ) }\end{array}$ & & & & 175,473 & $* *$ \\
\hline Yes & 1284 & 64.6 & 62.5 & 109,192 & 62.2 \\
\hline No & 709 & 35.6 & 37.5 & 66,281 & 37.8 \\
\hline
\end{tabular}

${ }^{a}$ The sample was weighted for age, race, and sex to reflect population proportions based on 2000 Census data. *Census data and sample subset includes persons age 25 and older. **Census data includes persons age 16 and older. 
for race, sex, age, and employment status suggest a sample comparable to Census data. The weighted data for these variables, which were used for analysis, adjusted the frequencies to reflect population proportions based on Census data.

Of the 1997 respondents, 191 were missing complete data on physical activity and/or one or more sociodemographic variables (age, race, sex, education, and employment status); therefore, the sample size for the analyses with physical activity level as the outcome was 1806 . Similarly, 1806 respondents had complete data for the analyses with walking as the outcome.

\section{Measures}

The questionnaire contained 82 items, including the six 2001 Behavioral Risk Factor Surveillance Survey (BRFSS) physical activity questions, ${ }^{25}$ three questions about walking behavior (parallel to the BRFSS questions), perceptions of the physical and social environment, and several individual-level variables. The BRFSS physical activity questions assess the number of days per week and total time spent per day for both moderate and vigorous physical activity separately. Agreement of $80 \%$ has been shown between simultaneous heart rate motion sensor and the BRFSS physical activity module in classifying persons who met the Centers for Disease Control and Prevention-American College of Sports Medicine (CDC-ACSM) ${ }^{26}$ recommendations. ${ }^{27}$ For this study, physical activity levels were computed into three categories: a) meeting the guidelines of moderate physical activity ( $\geq$ five times per week, $\geq 30$ min per day) or vigorous physical activity ( $\geq$ three times per week, $\geq 20$ min per day); b) insufficiently active (some physical activity, but less than the guidelines recommend); or c) inactive (no physical activity reported). For this article, the latter two categories were combined to create a dichotomous variable of "meets physical activity (PA) recommendation" or "does not meet PA recommendation."

Similarly, walking behavior was computed and categorized into a dichotomous variable of "regular walker" or "irregular/non-walker.” Regular walkers were defined consistent with the CDC definition for moderate-intensity activity ( $\geq$ five times per week, $\geq 30$ min per day). The walking questions asked about the frequency and duration of walking "for recreation, exercise, to get to and from places, while at work, or for any other reason." Self-efficacy was measured by the Self-Efficacy for Exercise Questionnaire. ${ }^{28}$ The 14-item scale asks subjects to rate their confidence to exercise (ranging from $0 \%$ to $100 \%$ ) in the face of barriers (e.g., when tired, depressed, in bad weather, have a hectic schedule, etc.). The original study showed the scale had high internal consistency (Cronbach's alpha $=0.90)$ and 12-month test-retest reliability $(r=0.67) .{ }^{28}$ Self-efficacy ratings from the scale have also been reported to be predictive of exercise adherence over a 12-month period. ${ }^{29}$ Among the same sample of respondents comprising this study sample, validity and reliability of this scale were consistent across gender, race, age, education, and body weight categories. Construct, convergent, and criterion-related validity were good and internal consistency was high $(\alpha=0.90$ to 0.94$)$ across all subgroups. ${ }^{30}$

The remaining independent variables assessed the respondents' perception of their physical and social environment. These variables were: 1) hear about a lot of places to be physically active (agree/disagree); 2) often hear about opportunities to be physically active (agree/disagree); 3) can usually find an exercise partner (agree/disagree); 4) seen physical activity advertisements in the past month 
(yes/no); 5) access to convenient indoor walking facility (yes/no); 6) number of known mapped out walking routes; 7) number of known mapped out bicycling routes; 8) number of parks, trails, and other recreation facilities available for use; 9) safety of recreational areas in the county that respondent may use for physical activity (safe/unsafe); 10) safety of trails from crime (safe/unsafe);11) condition of lighting in neighborhood (very good/good, fair/poor); 12) neighborhood sidewalks (no sidewalk, well maintained, not well maintained); 13) top perceived benefit to being physically active; and 14) top perceived barrier to being physically active. Variables 1 through 12 above were assessed using four 5-point response scales that offered subjects a range of responses. Responses to these questions were dichotomized (or collapsed into three levels in the case of item 12) for analysis due to skewed distributions.

\section{Statistical Analysis}

Initial analyses were conducted using logistic regressions separately for physical activity level (meets recommendation vs. does not meet recommendation) and for walking (regular vs. irregular/non-walker) with each independent variable, adjusted for age, sex, race, education, and employment status using SUDAAN software to account for the weighted data. Independent variables from these initial analyses that had a $p$ value $<0.05$ were entered into multivariate logistic regression models for physical activity level and walking and adjusted for age, sex, race, education, and employment. Variables were dropped from these two models if their respective $p$ values exceeded 0.05 . Two final models were computed, one for walking and one for physical activity level, with the final set of statistically significant variables.

\section{Results}

\section{Meeting the Physical Activity Recommendation}

\section{Subjects' Self-Reported Physical Activity Level and Sociodemographic}

Associations. The proportion of the sample that met the PA recommendation was $54.5 \%(n=985)$. This is somewhat higher than the levels of meeting the recommendation reported in 2003 BRFSS data for South Carolina (46.1\%) or for the US (45.9\%). ${ }^{3}$ As reported in Table 2, African Americans were less likely than Caucasians $(\mathrm{OR}=0.62)$; females were less likely than males $(\mathrm{OR}=0.76)$; and persons age $55 \mathrm{y}$ and older and persons age 34 to $54 \mathrm{y}$ were less likely than persons age 18 to $34 \mathrm{y}(\mathrm{OR}=0.59$ and 0.71 , respectively $)$ to meet the PA recommendation. Education and employment status were not significantly associated with meeting the PA recommendation.

Associations Between Perceived Individual, Social, and Environmental Factors and Meeting the PA Recommendation. Table 3 shows statistically significant initial associations (adjusted for age, race, sex, education, and employment) with meeting the PA recommendation. Self-efficacy was the strongest associate of PA level followed by being able to find an exercise partner, number of recreation facilities available for use, access to a convenient indoor walking facility, seeing 
Table 2 Associations Between Sociodemographic Variables and Meeting the Physical Activity Recommendation and Regular Walking $(n=1806)$

\begin{tabular}{|c|c|c|c|c|}
\hline Variable & $\begin{array}{l}\% \text { meeting PA } \\
\text { recommendation }\end{array}$ & OR & $95 \% \mathrm{Cl}$ & $p$ value \\
\hline \multicolumn{5}{|l|}{ Race } \\
\hline African American & 46.8 & 0.62 & $0.50,0.76$ & $<0.001$ \\
\hline Caucasian & 58.6 & 1.00 & Referent & \\
\hline Other & 52.1 & 0.77 & $0.45,1.30$ & 0.32 \\
\hline \multicolumn{5}{|l|}{ Age group (y) } \\
\hline $55+$ & 48.0 & 0.59 & $0.44,0.78$ & $<0.01$ \\
\hline $35-54$ & 52.5 & 0.71 & $0.56,0.89$ & $<0.01$ \\
\hline $18-34$ & 60.8 & 1.00 & Referent & \\
\hline \multicolumn{5}{|l|}{ Education } \\
\hline Less than high school & 48.7 & 0.75 & $0.43,1.31$ & 0.31 \\
\hline High school graduate & 53.8 & 0.92 & $0.55,1.54$ & 0.76 \\
\hline Some college & 55.3 & 0.98 & $0.60,1.62$ & 0.94 \\
\hline College graduate & 55.7 & 1.00 & Referent & \\
\hline \multicolumn{5}{|l|}{ Sex } \\
\hline Female & 51.0 & 0.76 & $0.62,0.93$ & 0.01 \\
\hline Male & 57.6 & 1.00 & Referent & \\
\hline \multicolumn{5}{|l|}{ Employed } \\
\hline Yes & 54.7 & 1.08 & $0.85,1.35$ & 0.53 \\
\hline No & 53.0 & 1.00 & Referent & \\
\hline Variable & $\begin{array}{c}\% \text { regular } \\
\text { walkers }\end{array}$ & OR & $95 \% \mathrm{Cl}$ & $p$ value \\
\hline \multicolumn{5}{|l|}{ Race } \\
\hline African American & 34.2 & 0.80 & $0.64,1.00$ & 0.05 \\
\hline Caucasian & 39.2 & 1.00 & Referent & \\
\hline Other & 41.1 & 1.09 & $0.64,1.85$ & 0.76 \\
\hline \multicolumn{5}{|l|}{ Age group (y) } \\
\hline $55+$ & 36.4 & 0.92 & $0.66,1.17$ & 0.38 \\
\hline $35-54$ & 36.7 & 0.90 & $0.71,1.12$ & 0.33 \\
\hline $18-34$ & 39.3 & 1.00 & Referent & \\
\hline \multicolumn{5}{|l|}{ Education } \\
\hline Less than high school & 36.7 & 0.78 & $0.48,1.56$ & 0.63 \\
\hline High school graduate & 35.9 & 0.76 & $0.49,1.42$ & 0.50 \\
\hline Some college & 38.4 & 0.83 & $0.56,1.55$ & 0.78 \\
\hline College graduate & 40.0 & 1.00 & Referent & \\
\hline \multicolumn{5}{|l|}{ Sex } \\
\hline Female & 36.3 & 0.91 & $0.73,1.10$ & 0.30 \\
\hline Male & 38.8 & 1.00 & Referent & \\
\hline \multicolumn{5}{|l|}{ Employed } \\
\hline Yes & 42.7 & 1.92 & $1.47,2.36$ & $<0.001$ \\
\hline No & 28.6 & 1.00 & Referent & \\
\hline
\end{tabular}

PA advertisements in the past month, number of known walking routes, and well maintained neighborhood sidewalks. Safety of trails from crime was significantly and negatively associated with meeting the PA recommendation (those who reported trails to be safe were less likely to meet the PA recommendation). 
Table 3 Significant and Non-Significant Adjusted Initial Associations of Individual, Social, and Environmental Factors with Physical Activity $(n=1806)$

\begin{tabular}{|c|c|c|c|c|c|}
\hline \multirow[b]{2}{*}{ Variable } & \multirow{2}{*}{$\begin{array}{l}\text { Weighted } \\
\text { response } \\
\text { (\%) for } \\
\text { total } \\
\text { sample }^{a}\end{array}$} & \multicolumn{4}{|c|}{ Meeting PA recommendation } \\
\hline & & $\begin{array}{c}\text { Adjusted } \\
\%\end{array}$ & $\begin{array}{l}\text { Adjusted } \\
\text { OR }\end{array}$ & $95 \% \mathrm{Cl}$ & $p$ value \\
\hline \multicolumn{6}{|l|}{$\begin{array}{l}\text { Self-efficacy for exercise } \\
(n=1805)^{\mathrm{b}}\end{array}$} \\
\hline Maximum = 1.00 & - & 82.0 & 21.81 & $13.29,35.80$ & $<0.001$ \\
\hline 3rd quartile $=0.75$ & & 67.9 & 10.09 & $6.96,14.64$ & \\
\hline Median $=0.57$ & & 55.0 & 5.80 & $4.37,7.69$ & \\
\hline 1 st quartile $=0.40$ & & 42.2 & 3.43 & $2.81,4.18$ & \\
\hline Minimum $=0.00$ & & 17.7 & 1.00 & Referent & \\
\hline \multicolumn{6}{|l|}{$\begin{array}{l}\text { Can usually find an } \\
\text { exercise partner } \\
(n=1776)\end{array}$} \\
\hline Agree & 70.0 & 56.6 & 1.55 & $1.24,1.92$ & $<0.001$ \\
\hline Disagree & 30.0 & 47.1 & 1.00 & Referent & \\
\hline \multicolumn{6}{|c|}{$\begin{array}{l}\text { Number of parks, trails, \& } \\
\text { other recreation facilities } \\
\text { available for use ( } n= \\
\text { 1806) }\end{array}$} \\
\hline $3+$ & 40.9 & 54.9 & 1.42 & $1.09,1.84$ & $<0.01$ \\
\hline $1-2$ & 34.2 & 58.2 & 1.57 & $1.20,2.06$ & $<0.001$ \\
\hline 0 & 24.9 & 46.7 & 1.00 & Referent & \\
\hline \multicolumn{6}{|c|}{$\begin{array}{l}\text { Access to convenient } \\
\text { indoor } \\
\text { walking facility }(n=1790)\end{array}$} \\
\hline Agree & 64.0 & 57.1 & 1.40 & $1.14,1.73$ & $<0.01$ \\
\hline Disagree & 36.0 & 48.7 & 1.00 & Referent & \\
\hline \multicolumn{6}{|l|}{$\begin{array}{l}\text { Seen physical activity } \\
\text { advertisements in past } \\
\text { month }(n=1776)\end{array}$} \\
\hline Yes & 44.2 & 58.4 & 1.37 & $1.12,1.68$ & $<0.01$ \\
\hline No & 55.8 & 50.8 & 1.00 & Referent & \\
\hline \multicolumn{6}{|c|}{$\begin{array}{l}\text { Number of known mapped } \\
\text { out walking routes } \\
(n=1806)\end{array}$} \\
\hline $3+$ & 17.8 & 60.1 & 1.38 & $1.06,1.81$ & 0.02 \\
\hline $1-2$ & 19.6 & 55.9 & 1.23 & $0.95,1.58$ & 0.12 \\
\hline 0 & 62.6 & 51.7 & 1.00 & Referent & \\
\hline \multicolumn{6}{|l|}{$\begin{array}{l}\text { Neighborhood sidewalks } \\
(n=1806)\end{array}$} \\
\hline Well maintained & 31.8 & 58.5 & 1.31 & $1.05,1.63$ & 0.02 \\
\hline Not well maintained & 5.2 & 51.1 & 0.96 & $0.61,1.51$ & 0.86 \\
\hline No sidewalk & 63.0 & 52.1 & 1.00 & Referent & \\
\hline \multicolumn{6}{|c|}{$\begin{array}{l}\text { Safety of trails from crime } \\
(n=1635)\end{array}$} \\
\hline Safe & 79.6 & 53.6 & 0.76 & $0.59,0.99$ & 0.04 \\
\hline Unsafe & 20.4 & 60.0 & 1.00 & Referent & \\
\hline
\end{tabular}




\begin{tabular}{|c|c|c|c|c|c|}
\hline \multirow[b]{2}{*}{ Variable } & \multirow{2}{*}{$\begin{array}{l}\text { Weighted } \\
\text { response } \\
(\%) \text { for } \\
\text { total } \\
\text { sample }^{a}\end{array}$} & \multicolumn{4}{|c|}{ Meeting PA recommendation } \\
\hline & & $\begin{array}{c}\text { Adjusted } \\
\%\end{array}$ & $\begin{array}{l}\text { Adjusted } \\
\text { OR }\end{array}$ & $95 \% \mathrm{Cl}$ & $p$ value \\
\hline \multicolumn{6}{|c|}{$\begin{array}{l}\text { Condition of street lighting } \\
\text { in neighborhood } \\
(n=1769)\end{array}$} \\
\hline Good & 44.4 & 57.0 & 1.22 & $1.00,1.49$ & 0.05 \\
\hline Fair/poor & 55.6 & 52.3 & 1.00 & Referent & \\
\hline \multicolumn{6}{|l|}{$\begin{array}{l}\text { Top benefit to being } \\
\text { physically active } \\
(n=1721)\end{array}$} \\
\hline Social/other & 13.2 & 60.7 & 1.34 & $0.98,1.84$ & 0.07 \\
\hline Weight loss & 6.0 & 58.9 & 1.25 & $0.81,1.91$ & 0.31 \\
\hline Self-esteem & 12.6 & 56.0 & 1.10 & $0.81,1.51$ & 0.54 \\
\hline Energy & 8.5 & 52.3 & 0.95 & $0.66,1.36$ & 0.76 \\
\hline Health & 59.8 & 53.7 & 1.00 & Referent & \\
\hline \multicolumn{6}{|l|}{$\begin{array}{l}\text { Often hear about } \\
\text { opportunities to be } \\
\text { physically active } \\
(n=1784)\end{array}$} \\
\hline Agree & 71.7 & 55.4 & 1.21 & $0.97,1.51$ & 0.08 \\
\hline Disagree & 28.3 & 50.8 & 1.00 & Referent & \\
\hline \multicolumn{6}{|l|}{$\begin{array}{l}\text { Top barrier to being } \\
\text { physically active } \\
(n=1509)\end{array}$} \\
\hline Illness/injury & 15.7 & 56.7 & 1.13 & $0.80,1.58$ & 0.49 \\
\hline Other & 18.0 & 56.4 & 1.11 & $0.82,1.51$ & 0.48 \\
\hline Tiring/hard to do & 12.7 & 47.5 & 0.77 & $0.54,1.11$ & 0.16 \\
\hline Attitude & 8.5 & 48.1 & 0.79 & $0.56,1.18$ & 0.25 \\
\hline Time & 45.1 & 53.8 & 1.00 & Referent & \\
\hline \multicolumn{6}{|c|}{$\begin{array}{l}\text { Hear about a lot of places } \\
\text { to be physically active } \\
(n=1788)\end{array}$} \\
\hline Agree & 74.2 & 55.0 & 1.16 & $0.94,1.45$ & 0.20 \\
\hline Disagree & 25.8 & 51.5 & 1.00 & Referent & \\
\hline \multicolumn{6}{|c|}{$\begin{array}{l}\text { Number of known mapped } \\
\text { out bicycling routes } \\
(n=1806)\end{array}$} \\
\hline $3+$ & 7.6 & 58.2 & 1.23 & $0.83,1.81$ & 0.31 \\
\hline $1-2$ & 18.8 & 55.3 & 1.09 & $0.85,1.40$ & 0.51 \\
\hline None & 73.6 & 53.3 & 1.00 & Referent & \\
\hline \multicolumn{6}{|c|}{$\begin{array}{l}\text { Safety of recreational areas } \\
\text { in the county }(n=1665)\end{array}$} \\
\hline Safe & 89.1 & 54.4 & 0.87 & $0.62,1.23$ & 0.42 \\
\hline Unsafe & 10.9 & 57.6 & 1.00 & Referent & \\
\hline
\end{tabular}

aThe sample was weighted for age, race, and sex to reflect population proportions based on 2000 Census

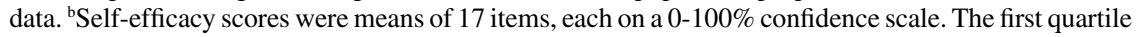
of self-efficacy scores was $40 \%$ confidence and the third quartile was $75 \%$ percent confidence. Significance level was $p<0.05$. Models were adjusted for age, sex, race, education, and employment. 
Variables that were not statistically significant were hearing about a lot of places to be physically active, hearing about opportunities to be physically active, number of known bicycle routes, safety of areas in the county for physical activity, condition of lighting in neighborhood, and the top perceived benefit and barrier to being physically active.

Multivariate Model for Meeting the PA Recommendation. In the final model for meeting the PA recommendation, shown in Table 4, self-efficacy remained the strongest associate of meeting the recommendation. Being able to find an exercise partner and knowing of one to two parks, trails, or other recreational areas available for use were significantly and positively associated with meeting the PA recommendation. Safety of trails from crime remained significant (negatively associated) in the multivariate model as well.

Table 4 Final Multivariate Model of Individual, Social, and Environmental Factors Associated with Physical Activity $(n=1612)$

\begin{tabular}{|c|c|c|c|c|}
\hline Variable & $\begin{array}{c}\text { Adjusted \% } \\
\text { meeting PA } \\
\text { recomm. }\end{array}$ & $\begin{array}{c}\text { Adjusted OR } \\
\text { meeting PA } \\
\text { recomm. } \\
\end{array}$ & $95 \% \mathrm{Cl}$ & $p$ value \\
\hline \multicolumn{5}{|l|}{$\begin{array}{l}\text { Self-efficacy for } \\
\text { exercise }^{a}\end{array}$} \\
\hline Maximum $=1.00$ & 81.1 & 19.19 & $11.30,32.60$ & $<0.001$ \\
\hline 3rd quartile $=0.75$ & 67.6 & 9.17 & $6.16,13.64$ & \\
\hline Median $=0.57$ & 55.4 & 5.39 & $3.98,7.29$ & \\
\hline 1st quartile $=0.40$ & 43.3 & 3.26 & $2.64,4.03$ & \\
\hline Minimum $=0.00$ & 19.4 & 1.00 & Referent & \\
\hline \multicolumn{5}{|l|}{$\begin{array}{l}\text { Can usually find an } \\
\text { exercise partner }\end{array}$} \\
\hline Agree & 57.0 & 1.47 & $1.15,1.89$ & $<0.01$ \\
\hline Disagree & 48.6 & 1.00 & Referent & \\
\hline \multicolumn{5}{|l|}{$\begin{array}{l}\text { Number of parks, } \\
\text { trails, \& other } \\
\text { recreation facilities } \\
\text { available for use }\end{array}$} \\
\hline $3+$ & 54.5 & 1.31 & $0.95,1.79$ & 0.10 \\
\hline $1-2$ & 58.0 & 1.54 & $1.12,2.12$ & $<0.01$ \\
\hline 0 & 48.7 & 1.00 & Referent & \\
\hline \multicolumn{5}{|l|}{$\begin{array}{l}\text { Safety of trails from } \\
\text { crime }\end{array}$} \\
\hline Safe & 53.2 & 0.72 & $0.55,0.95$ & 0.02 \\
\hline Unsafe & 60.1 & 1.00 & Referent & \\
\hline
\end{tabular}

aself-efficacy scores were means of 17 items, each on a $0-100 \%$ confidence scale. The first quartile of self-efficacy scores was $40 \%$ confidence and the third quartile was $75 \%$ percent confidence. Model was adjusted for age, sex, race, education, and employment. 
Table 5 Significant and Non-Significant Adjusted Initial Associations of Individual, Social, and Environmental Factors with Regular Walking $(n=1806)$

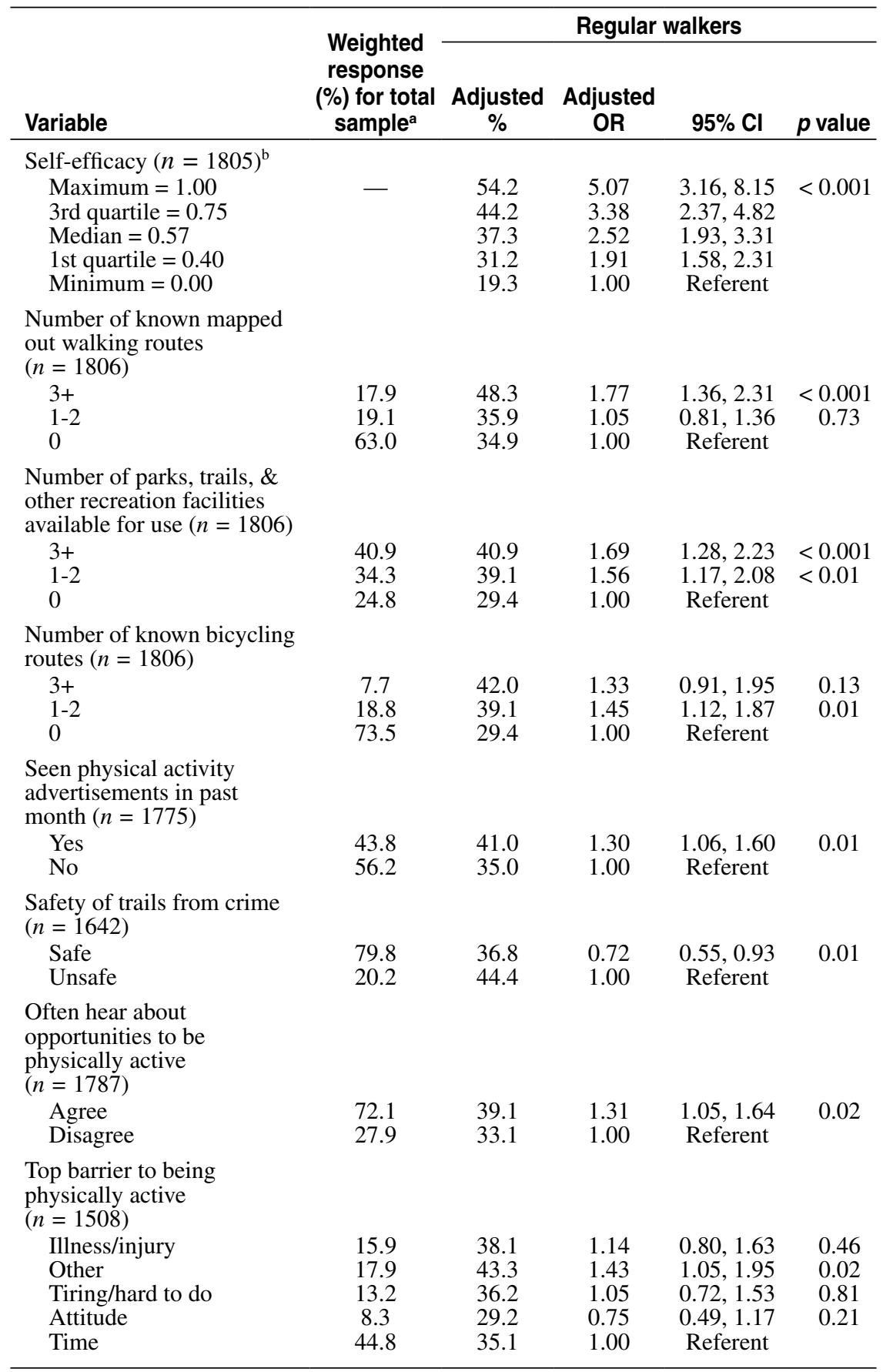




\begin{tabular}{|c|c|c|c|c|c|}
\hline \multirow[b]{2}{*}{ Variable } & \multirow{2}{*}{$\begin{array}{l}\text { Weighted } \\
\text { response } \\
\text { (\%) for total } \\
\text { sample }^{\mathrm{a}}\end{array}$} & \multicolumn{4}{|c|}{ Regular walkers } \\
\hline & & $\begin{array}{c}\text { Adjusted } \\
\% \\
\end{array}$ & $\begin{array}{l}\text { Adjusted } \\
\text { OR } \\
\end{array}$ & $95 \% \mathrm{Cl}$ & $p$ value \\
\hline \multicolumn{6}{|l|}{$\begin{array}{l}\text { Neighborhood sidewalks } \\
(n=1806)\end{array}$} \\
\hline Well maintained & 32.1 & 40.8 & 1.26 & $1.01,1.58$ & 0.04 \\
\hline Not well maintained & 5.1 & 42.2 & 1.34 & $0.84,2.13$ & 0.22 \\
\hline No sidewalk & 62.8 & 35.5 & 1.00 & Referent & \\
\hline \multicolumn{6}{|l|}{$\begin{array}{l}\text { Top benefit to being } \\
\text { physically active } \\
(n=1722)\end{array}$} \\
\hline Social/other & 12.9 & 38.8 & 1.05 & $0.76,1.45$ & 0.76 \\
\hline Weight loss & 5.8 & 29.3 & 0.68 & $0.43,1.07$ & 0.10 \\
\hline Self-esteem & 12.7 & 41.5 & 1.18 & $0.86,1.63$ & 0.31 \\
\hline Energy & 8.9 & 41.3 & 1.17 & $0.83,1.66$ & 0.37 \\
\hline Health & 59.7 & 37.6 & 1.00 & Referent & \\
\hline \multicolumn{6}{|c|}{$\begin{array}{l}\text { Can usually find an exercise } \\
\text { partner }(n=1775)\end{array}$} \\
\hline Agree & 69.9 & 38.7 & 1.21 & $0.97,1.51$ & 0.10 \\
\hline Disagree & 30.1 & 34.4 & 1.00 & Referent & \\
\hline \multicolumn{6}{|l|}{$\begin{array}{l}\text { Hear about a lot of places } \\
\text { to be physically active } \\
(n=1786)\end{array}$} \\
\hline Agree & 74.5 & 37.9 & 1.12 & $0.89,1.41$ & 0.34 \\
\hline Disagree & 25.5 & 35.4 & 1.00 & Referent & \\
\hline \multicolumn{6}{|l|}{$\begin{array}{l}\text { Access to convenient } \\
\text { indoor walking facility } \\
(n=1791)\end{array}$} \\
\hline Yes & 64.0 & 37.9 & 1.04 & $0.84,1.29$ & 0.71 \\
\hline No & 36.0 & 37.0 & 1.00 & Referent & \\
\hline \multicolumn{6}{|c|}{$\begin{array}{l}\text { Safety of recreational areas } \\
\text { in the county }(n=1671)\end{array}$} \\
\hline Safe & 88.8 & 38.0 & 0.95 & $0.68,1.31$ & 0.75 \\
\hline Unsafe & 11.2 & 39.3 & 1.00 & Referent & \\
\hline \multicolumn{6}{|c|}{$\begin{array}{l}\text { Condition of street lighting } \\
\text { in neighborhood }(n=1769)\end{array}$} \\
\hline Good & 44.9 & 38.0 & 1.02 & $0.83,1.26$ & 0.84 \\
\hline Fair/poor & 55.1 & 37.6 & 1.00 & Referent & \\
\hline
\end{tabular}

${ }^{a}$ The sample was weighted for age, race, and sex to reflect population proportions based on 2000 Census data. ${ }^{b}$ Self-efficacy scores were means of 17 items, each on a $0-100 \%$ confidence scale. The first quartile of self-efficacy scores was $40 \%$ confidence and the third quartile was $75 \%$ percent confidence. Significance level was $p<0.05$. Models were adjusted for age, sex, race, education, and employment. Regular walking was defined as walking for at least $30 \mathrm{~min}$ on $5 \mathrm{~d} / \mathrm{wk}$.

\section{Walking Regularly}

Subjects' Self-Reported Walking and Association with Sociodemographic Variables. The proportion of the sample that walked regularly was $38.0 \%$ ( $n$ $=687$ ). This is similar to the prevalence of regular walking reported in a recent national study (34\%). ${ }^{13}$ As reported in Table 2, persons employed outside the home 
were more likely to be regular walkers than those who did not work outside the home $(\mathrm{OR}=1.92)$. Age, race, sex, and education were not significantly associated with walking.

\section{Associations Between Perceived Individual, Social, and Environmental Factors} and Regular Walking. Table 5 presents the significant initial associations with regular walking behavior. Self-efficacy and number of known walking routes were the strongest positive associations with regular walking, followed by the number of parks, trails, and other recreational areas available for use; number of known bicycling routes; seeing physical activity advertisements in the past month; often hearing about opportunities to be physically active; "other" barriers to being physically active (other than illness/injury, tiring/hard to do, attitude, or time); and well maintained neighborhood sidewalks. Safety of trails from crime was negatively associated with regular walking (those reporting trails to be safe were less likely to walk regularly).

Variables that were not statistically significant were hearing about a lot of places to be physically active, being able to find an exercise partner, access to convenient indoor walking facility, safety of areas in the county for physical activity, condition of lighting in neighborhood, condition of neighborhood sidewalks, and an individual's top perceived benefit to being physically active (the top benefits reported, in descending order, were: time, illness/injury, tiring/hard to do, attitude).

Multivariate Model for Regular Walking. In the final model for walking shown in Table 6, self-efficacy was the strongest associate of walking. Knowing of three or more walking routes and knowing of any available parks, trails, or other recreational areas were positively and significantly associated with regular walking as well. Safety of trails from crime remained significant (negatively associated) in the multivariate model as well.

\section{Discussion}

Consistent with other studies, self-efficacy was the strongest association with both physical activity and regular walking in the adjusted multivariate models. ${ }^{18}$ Perceived environmental variables were also associated with both physical activity and regular walking-knowing of one to two parks, trails, or other recreation facilities was associated with both physical activity and walking. The number of known walking routes was also significantly associated with walking. A recent meta-analysis found significant, positive adjusted odds ratios between physical activity and several perceived environmental variables, including the perceived presence of facilities $(\mathrm{OR}=1.20)$, sidewalks $(\mathrm{OR}=1.23)$, shops and services $(\mathrm{OR}=1.30)$, as well as with the perception that traffic was not a problem $(\mathrm{OR}=1.22) .{ }^{31}$

In addition, safety of trails from crime was negatively associated in multivariate models with both physical activity and regular walking. Persons meeting the PA recommendation and regular walkers in this study were more likely to report that trails were unsafe related to crime. This may seem counterintuitive given reports in other studies that safety or perceived safety has been associated with greater levels of physical activity behaviors. ${ }^{32,33}$ It may be that perceptions about safety of trails from crime were influenced by more frequent use of these trails or greater attention to or weight placed upon either perceived or real safety concerns in trail areas. 
Table 6 Final Multivariate Model of Individual, Social, and Environmental Factors Associated with Regular Walking $(N=1641)$

\begin{tabular}{|c|c|c|c|c|}
\hline Variable & $\begin{array}{c}\text { Adjusted } \\
\% \text { regular } \\
\text { walkers }\end{array}$ & $\begin{array}{c}\text { Adjusted } \\
\text { OR } \\
\text { regular } \\
\text { walkers } \\
\end{array}$ & $95 \% \mathrm{Cl}$ & $p$ value \\
\hline \multicolumn{5}{|l|}{ Self-efficacy ${ }^{\mathrm{a}}$} \\
\hline Maximum $=1.00$ & 52.6 & 4.22 & $2.55,6.98$ & $<0.0001$ \\
\hline 3rd quartile $=0.75$ & 44.0 & 2.94 & $2.02,4.29$ & \\
\hline Median $=0.57$ & 38.0 & 2.27 & $1.70,3.03$ & \\
\hline 1st quartile $=0.40$ & 32.7 & 1.78 & $1.45,2.18$ & \\
\hline Minimum $=0.00$ & 21.8 & 1.00 & Referent & \\
\hline \multicolumn{5}{|c|}{$\begin{array}{l}\text { Number of known mapped } \\
\text { out walking routes }\end{array}$} \\
\hline $3+$ & 46.2 & 1.54 & $1.15,2.06$ & $<0.001$ \\
\hline $1-2$ & 36.0 & 0.98 & $0.74,1.29$ & 0.88 \\
\hline 0 & 36.5 & 1.00 & Referent & \\
\hline \multicolumn{5}{|c|}{$\begin{array}{l}\text { Number of parks, trails, and } \\
\text { other recreation facilities } \\
\text { available for use }\end{array}$} \\
\hline $3+$ & 40.4 & 1.59 & $1.15,2.19$ & $<0.01$ \\
\hline $1-2$ & 40.1 & 1.57 & $1.14,2.18$ & $<0.01$ \\
\hline 0 & 30.4 & 1.00 & Referent & \\
\hline \multicolumn{5}{|c|}{ Safety of trails from crime } \\
\hline Safe & 36.7 & 0.69 & $0.52,0.91$ & $<0.01$ \\
\hline Unsafe & 44.9 & 1.00 & Referent & \\
\hline
\end{tabular}

a Self-efficacy scores were means of 17 items, each on a $0-100 \%$ confidence scale. The first quartile of self-efficacy scores was $40 \%$ confidence and the third quartile was $75 \%$ percent confidence. Model was adjusted for age, sex, race, education, and employment.

This study also found a social support variable (finding an exercise partner) was associated with physical activity. The associations between being able to find an exercise partner and physical activity were not, however, at a level much different than that of the perceived environmental variables (recreational facilities available for use and safety of trails from crime). These findings are similar to other studies comparing associations of individual, social, and environmental variables with physical activity and walking that did not find much difference in these types of variables in their strength of association with physical activity or walking. ${ }^{19,22,23}$ Other studies, however, have found social variables to be more strongly associated with behavior than environmental variables. ${ }^{18,21}$ The results of this study also contribute to other evidence in the literature that factors influencing behavior may differ for physical activity and walking. ${ }^{18-23}$

The results of this study, in conjunction with other methods of formative research (e.g., focus groups), were used to inform the development of a social marketing campaign to promote moderate-intensity physical activity. Implications of this study for that campaign included emphasizing the promotion of the multiple existing trails, walking routes, parks, and recreation facilities in the county, as well as activities to enhance self-efficacy and to facilitate the location of social 
support/exercise partners. Future research may determine whether modifications of the physical or social environment influence levels of self-efficacy and how effectively the environment may influence behavior directly.

This study was conducted with a large, diverse random sample and included a high percentage of African Americans. In addition, the study was conducted in a southeastern state in a region with a high prevalence of physical activity-related disease burden (i.e., stroke, diabetes, obesity). ${ }^{34,35}$ There are, however, limitations to the study. The low response rate may have biased the results; however, the rates of regular walking and of meeting the PA recommendation were similar to other studies we have conducted in these two counties, as well as national prevalence rates. In addition, the results should be considered in light of the self-reported data and that this sample reported a higher education level than found in the 2000 US Census. The questions used to assess walking did not separate walking to get to and from places from walking for exercise or recreation. Some research suggests that the determinants of walking for recreation or exercise may be different than determinants of walking for transportation purposes. ${ }^{16}$ Lastly, it is always important to consider that statistical significance may not equal practical importance.

The questions used in this study were selected in order to evaluate a community-based intervention based on objectives created in partnership with a community coalition. They do not represent the full array of potential personal, social, and environmental factors suggested by the Socioecologic Model, ${ }^{6}$ nor all of the factors that have been significantly associated with physical activity and walking in other studies; however, this study did include several variables that have not been previously explored. The stronger association of self-efficacy to behavior compared to other variables may be explained in part by the reliability and validity of this measure compared to that for perceived environmental or social factors. Questions about the physical environment are difficult to validate, as objective data for this purpose is scarce; however, if the environment does influence physical activity and walking behaviors, it may be that perceptions of the environment are qualitatively more important than objective indicators in predicting behavior. Our previous validation studies with similar single-item indicators of the community environment by self-report revealed only moderate validity compared to objective measures. ${ }^{36}$

Nevertheless, the robust association of self-efficacy with behavior confirms its importance in association with behavior; and this study suggests that it may be more important than the social and environmental factors measured in this study for physical activity in general and walking in particular. Continued measurement development and testing may improve attempts to determine the levels of influence of social and physical environmental factors. ${ }^{5,16}$ Longitudinal studies and studies designed to influence self-efficacy and/or to manipulate aspects of the social and physical environment are needed to elucidate causal associations.

Results of this study support previous findings related to factors associated with physical activity in general and walking behaviors more specifically (e.g., self-efficacy, social support, recreational areas, sidewalks). Results also identified additional variables for further investigation (e.g., environmental prompts) that may influence physical activity behaviors. The study contributes additional evidence to the literature regarding ecological influences on physical activity behavior that may better inform future intervention efforts designed to reduce sedentary behaviors and increase regular physical activity. 


\section{Acknowledgments}

The first author was with the University of South Carolina, Prevention Research Center at the time of this study. This study was supported by grant number R06/CCR421479 and by cooperative agreement number U48/CCU409664 and 1-U48-DP-000051 from the Centers for Disease Control and Prevention. Its contents are solely the responsibility of the authors and do not necessarily represent the official views of the Centers for Disease Control and Prevention. The authors appreciate the contributions of Lara Peck, Ericka Burroughs, and the Sumter County Active Lifestyles Coalition.

\section{References}

1. Kesaniemi YK, Danforth E, Jr., Jensen MD, Kopelman PG, Lefebvre P, Reeder BA. Dose-response issues concerning physical activity and health: an evidence-based symposium. Med Sci Sports Exerc. 2001;33(suppl 6):S351-S358.

2. Services UDoHaH. Physical activity and health: a report of the Surgeon General. Atlanta, GA: Centers for Disease Control and Prevention; 1996.

3. (CDC). CfDCaP. Behavioral Risk Factor Surveillance System Survey Data. Atlanta, GA: US Dept of Health and Human Services, Centers for Disease Control and Prevention; 2003.

4. Simpson ME, Serdula M, Galuska DA, et al. Walking trends among U.S. adults: The Behavioral Risk Factor Surveillance System, 1987-2000. Am J Prev Med. 2003/8 2003;25:95-100.

5. Giles-Corti B, Timperio A, Bull F, Pikora T. Understanding physical activity environmental correlates: increased specificity for ecological models. Exerc Sport Sci Rev. 2005;33:175-181.

6. McLeroy KR, Bibeau D, Steckler A, Glanz K. An ecological perspective on health promotion programs. Health Educ Q. 1988;15:351-377.

7. Booth SL, Sallis JF, Ritenbaugh C, et al. Environmental and societal factors affect food choice and physical activity: rationale, influences, and leverage points. Nutr Rev. 2001;59(3 pt 2):S21-S39; discussion S57-S65.

8. Sallis JF, Owen NG. Physical Activity and Behavioral Medicine. Thousand Oaks, CA: Sage Publications; 1999.

9. Trost SG, Owen N, Bauman AE, Sallis JF, Brown W. Correlates of adults' participation in physical activity: review and update. Med Sci Sports Exerc. 2002;34:1996-2001.

10. Cervero R, Duncan M. Walking, bicycling, and urban landscapes: evidence from the San Francisco Bay Area. Am J Public Health. 2003;93:1478-1483.

11. Frank LD, Schmid TL, Sallis JF, Chapman J, Saelens BE. Linking objectively measured physical activity with objectively measured urban form: Findings from SMARTRAQ. Am J Prev Med. 2005;28(2, suppl 2):117-125.

12. Handy SL, Boarnet MG, Ewing R, Killingsworth RE. How the built environment affects physical activity: views from urban planning. Am J Prev Med. 2002;23(suppl 2):64-73.

13. Eyler AA, Brownson RC, Bacak SJ, Housemann RA. The epidemiology of walking for physical activity in the United States. Med Sci Sports Exerc. 2003;35:1529-1536.

14. Giles-Corti B, Broomhall MH, Knuiman M, et al. Increasing walking: How important is distance to, attractiveness, and size of public open space? Am J Prev Med. 2005;28(suppl 2):169-176.

15. Suminski RR, Poston WSC, Petosa RL, Stevens E, Katzenmoyer LM. Features of the neighborhood environment and walking by U.S. adults. Am J Prev Med. 2005;28:149-155.

16. Owen N, Humpel N, Leslie E, Bauman A, Sallis JF. Understanding environmental influences on walking; Review and research agenda. Am J Prev Med. 2004;27:67-76. 
17. Craig CL, Brownson RC, Cragg SE, Dunn AL. Exploring the effect of the environment on physical activity: a study examining walking to work. Am J Prev Med. 2002;23(suppl 2):36-43.

18. Burton NW, Turrell G, Oldenburg B, Sallis JF. The relative contributions of psychological, social, and environmental variables to explain participation in walking, moderate-, and vigorous-intensity leisure-time physical activity. J Phys Act Health. 2005;2:181-196.

19. Duncan M, Mummery K. Psychosocial and environmental factors associated with physical activity among city dwellers in regional Queensland. Prev Med. 2005;40:363-372.

20. Addy CL, Wilson DK, Kirtland KA, Ainsworth BE, Sharpe P, Kimsey D. Associations of perceived social and physical environmental supports with physical activity and walking behavior. Am J Public Health. 2004;94:440-443.

21. Giles-Corti B, Donovan RJ. The relative influence of individual, social and physical environment determinants of physical activity. Soc Sci Med. 2002;54:1793-1812.

22. Hoehner CM, Brennan Ramirez LK, Elliott MB, Handy SL, Brownson RC. Perceived and objective environmental measures and physical activity among urban adults. Am J Prev Med. 2005;28(2, suppl 2):105-116.

23. Giles-Corti B, Donovan RJ. Relative influences of individual, social environmental, and physical environmental correlates of walking. Am J Public Health. 2003;93:15831589 .

24. Humpel N, Owen N, Iverson D, Leslie E, Bauman A. Perceived environment attributes, residential location, and walking for particular purposes. Am J Prev Med. 2004;26:119-125.

25. (CDC). CfDCaP. Behavioral Risk Factor Surveillance System Survey Questionnaire. Atlanta, GA: US Dept of Health and Human Services, Centers for Disease Control and Prevention; 2001.

26. Pate RR, Pratt M, Blair SN, et al. Physical activity and public health. A recommendation from the Centers for Disease Control and Prevention and the American College of Sports Medicine. JAMA. 1995;273:402-407.

27. Strath SJ, Bassett DR Jr, Ham SA, Swartz AM. Assessment of physical activity by telephone interview versus objective monitoring. Med Sci Sports Exerc. 2003;35:21122118.

28. Garcia AW, King A. Predicting long-term adherence to aerobic exercise: A comparison of two models. J Sport Exerc Psychol. 1991;13:394-410.

29. Brassington GS, Atienza AA, Perczek RE, DiLorenzo TM, King AC. Interventionrelated cognitive versus social mediators of exercise adherence in the elderly. Am J Prev Med. 2002;23:80-86.

30. Wilcox S, Sharp PA, Hutto B, Granner ML. Psychometric properties of the Self-Efficacy for Exercise Questionnaire in a diverse sample of men and women. $J$ Phys Act Health. 2005;2:285-297.

31. Duncan MJ, Spence JC, Mummery WK. Perceived environment and physical activity: a meta-analysis of selected environmental characteristics. Int J Behav Nutr Phys Act. 2005;2:11.

32. CDC. CfDCaP. Perceptions of neighborhood characteristics and leisure-time physical inactivity-Austin/Travis County, Texas, 2004. MMWR Morb Mortal Wkly Rep. 2005;54:926-928.

33. Li F, Fisher KJ, Brownson RC, Bosworth M. Multilevel modelling of built environment characteristics related to neighbourhood walking activity in older adults. J Epidemiol Community Health. 2005;59:558-564.

34. (CDC). CfDCaP. Regional and racial differences in prevalence of stroke-23 states and District of Columbia, 2003. MMWR Morb Mortal Wkly Rep.2005;54:481-484.

35. Mokdad AH, Ford ES, Bowman BA, et al. Prevalence of obesity, diabetes, and obesityrelated health risk factors, 2001. Jama. 2003;289:76-79.

36. Kirtland KA, Porter DE, Addy CL, et al. Environmental measures of physical activity supports: perception versus reality. Am J Prev Med. 2003;24:323-331. 